\title{
A transition-metal-free access to heteroaromatic-fused 4-tetralones by the oxidative ring expansion of the cyclobutanol moiety
}

\section{X-Ray Crystallography Supplementary Information}

Philipp Natho, Lewis A. T. Allen, Andrew J. P. White \& Philip J. Parsons*

Department of Chemistry, Imperial College London, Molecular Sciences Research Hub, W12 0BZ, London, U.K.

\author{
Corresponding Author: $\quad$ Philip J. Parsons \\ E-Mail: $\quad$ p.parsons@imperial.ac.uk \\ ORCID: $\quad$ Philip J. Parsons: 0000-0002-9158-4034
}

Table of Contents

X-Ray Crystal Structure Data for Compounds 20 and 23..............................S2

Figures of X-Ray Crystal Structures for Compounds 20 and 23 ......................S3 


\section{X-Ray Crystal Structure Data for Compounds 20 and 23}

\section{The X-ray crystal structure of 20}

Single crystals for X-ray analysis were crystallized by liquid-liquid diffusion between chloroform and diethyl ether.

Crystal data for 20: $\mathrm{C}_{19} \mathrm{H}_{16} \mathrm{FNO}_{3} \mathrm{~S}, M=357.39$, monoclinic, $P 2_{1} / c$ (no. 14), $a=12.1600(7)$, $b=8.8150(4), c=15.9312(9) \AA, \beta=105.042(6)^{\circ}, V=1649.15(16) \AA^{3}, Z=4, D_{\mathrm{c}}=1.439 \mathrm{~g} \mathrm{~cm}^{-}$ ${ }^{3}, \mu(\mathrm{Mo}-\mathrm{K} \alpha)=0.225 \mathrm{~mm}^{-1}, T=173 \mathrm{~K}$, colourless platy needles, Agilent Xcalibur $3 \mathrm{E}$ diffractometer; 3359 independent measured reflections $\left(R_{\text {int }}=0.0181\right), F^{2}$ refinement, ${ }^{1,2}$ $R_{1}$ (obs) $=0.0530, w R_{2}($ all $)=0.1325,2606$ independent observed absorption-corrected reflections $\left[\left|F_{\mathrm{o}}\right|>4 \sigma\left(\left|F_{\mathrm{o}}\right|\right)\right.$, completeness to $\left.\theta_{\text {full }}\left(25.2^{\circ}\right)=99.1 \%\right], 227$ parameters. CCDC 1915241.

\section{The X-ray crystal structure of 23}

Single crystals for X-ray analysis were crystallized by slow evaporation from chloroform.

Crystal data for 23: $\mathrm{C}_{19} \mathrm{H}_{17} \mathrm{~F}_{2} \mathrm{NO}_{3} \mathrm{~S}, M=377.39$, monoclinic, $P 2_{1} / n$ (no. 14), $a=9.3694(3)$, $b=14.7085(4), c=12.9376(4) \AA, \beta=103.951(3)^{\circ}, V=1730.34(10) \AA^{3}, Z=4, D_{\mathrm{c}}=1.449 \mathrm{~g}$ $\mathrm{cm}^{-3}, \mu(\mathrm{Mo}-\mathrm{K} \alpha)=0.227 \mathrm{~mm}^{-1}, T=173 \mathrm{~K}$, colourless tablets, Agilent Xcalibur $3 \mathrm{E}$ diffractometer; 3455 independent measured reflections $\left(R_{\text {int }}=0.0165\right), F^{2}$ refinement, ${ }^{1,2}$ $R_{1}$ (obs) $=0.0370, w R_{2}($ all $)=0.0939,2833$ independent observed absorption-corrected reflections $\left[\left|F_{\mathrm{o}}\right|>4 \sigma\left(\left|F_{\mathrm{o}}\right|\right)\right.$, completeness to $\left.\theta_{\text {full }}\left(25.2^{\circ}\right)=98.6 \%\right], 246$ parameters. CCDC 1915242.

The $\mathrm{C} 10$-based $\mathrm{C}_{4}$ ring in the structure of $\mathbf{2 3}$ was found to be disordered. Two sites for the $\mathrm{C} 12 \mathrm{CH}_{2}$ moiety and the associated hydrogen atoms on $\mathrm{C} 11$ and $\mathrm{C} 13$ were identified, of $c a .88$ and $12 \%$ occupancy. The geometries of the two orientations were optimised, the thermal parameters of the two partial occupancy carbon atoms were restrained to be similar, and only the carbon atom of the major occupancy orientation was refined anisotropically (that of the minor occupancy orientation was refined isotropically). The $\mathrm{O} 14-\mathrm{H}$ hydrogen atom was located from a $\Delta F$ map and refined freely subject to an $\mathrm{O}-\mathrm{H}$ distance constraint of $0.90 \AA$.

\section{References}

1. SHELXTL v5.1, Bruker AXS, Madison, WI, 1998.

2. SHELX-2013, G.M. Sheldrick, Acta Cryst., 2015, C71, 3-8. 
Figures of X-Ray Crystal Structures for Compounds 20 and 23

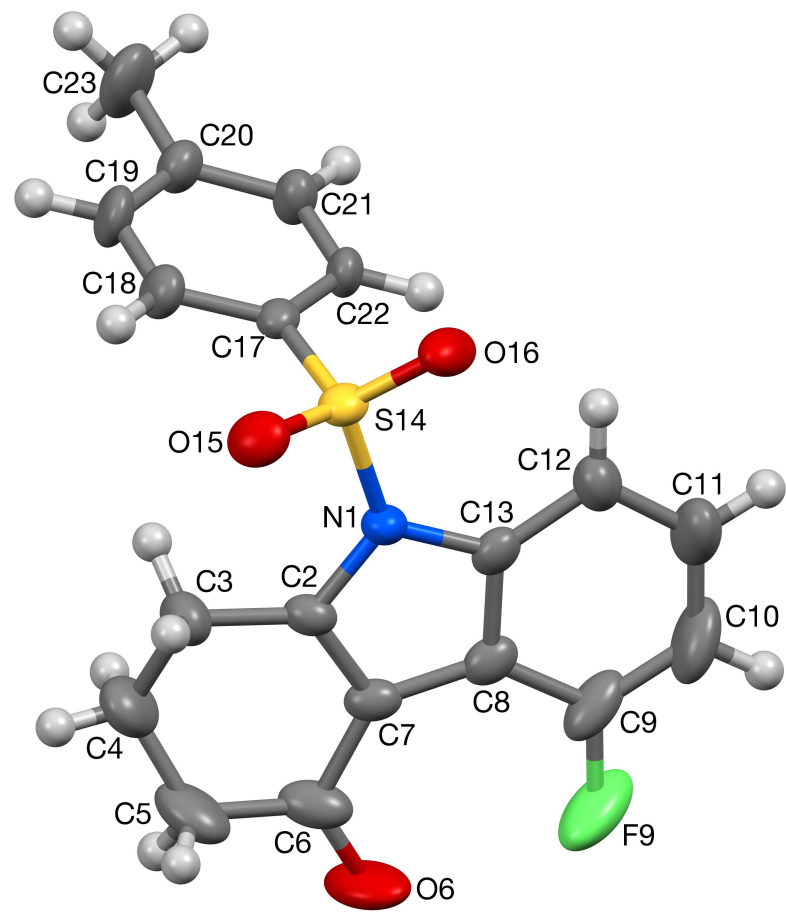

Fig. S1 The crystal structure of $\mathbf{2 0}$ (50\% probability ellipsoids).

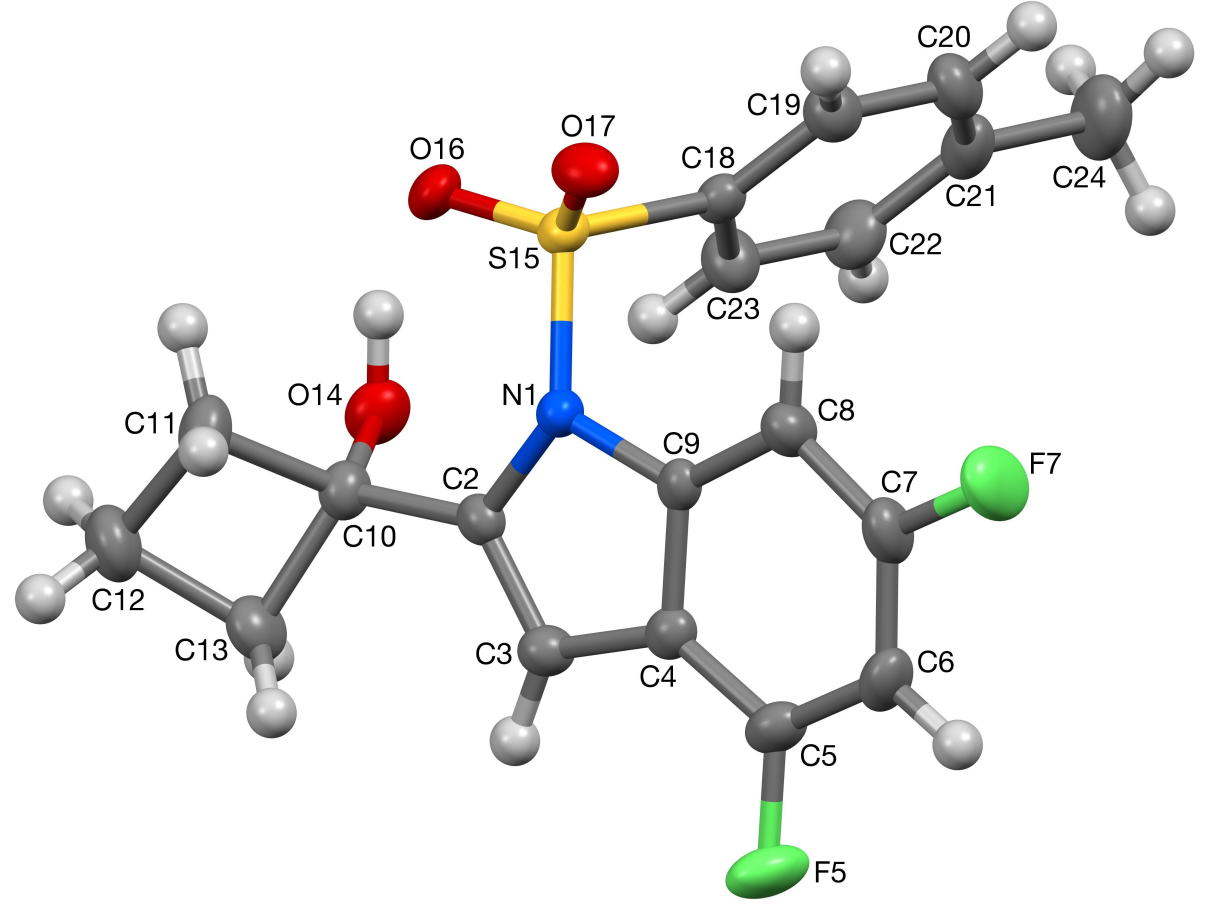

Fig. S2 The crystal structure of $\mathbf{2 3}$ (50\% probability ellipsoids). 